\title{
Analysis of Machined Electron Beam Treated Ti6AI4V-ELI Implant Surfaces
}

\author{
Miroslav Piska*, Katrin Buckova \\ Brno University of Technology, Faculty of Mechanical Engineering, Brno, 61669, Czech Republic \\ *Corresponding author: Tel: (+420) 541142555; E-mail: piska@fme.vutbr.cz
}

Received: 15 August 2018, Revised: 09 January 2019 and Accepted: 11 January 2019

DOI: $10.5185 /$ amlett.2019.2229

www.vbripress.com/aml

\begin{abstract}
This work contributes to the problem of individual replacements of human joints by applying new types of implants and materials, made using modern additive technologies (melting of metal powders by laser and electron beam). The main attention is paid to the method called Electron Beam Melting used with the ARCAM Q10plus machine. Analyses of the sintered Ti6A14V - ELI alloy samples were made from the point of view of production precision and quality after sintering in different technological modes and the surface quality reached after turning and tumbling, including measurement of other physical quantities. The results confirm an important effect of sample inclination in the chamber when building on the precision of the shape and quality of the surface. The tensile strengths were high (up to 1,012 $\mathrm{MPa}$ ) and statistically consistent. Furthermore, the material exhibited high resistance to machining, expressed in terms of force loading and specific cutting forces, measured for a range of feed per rotation $0.05-0.40 \mathrm{~mm}$, cutting speed $48 \mathrm{~m} / \mathrm{min}$, depth of cut $1.0 \mathrm{~mm}$ and use of coated cemented carbides, in dry cutting conditions. Nevertheless, a high quality after machining can be reached. The quality can be improved more by two-steps tumbling technology so finally a glossy surface $(\mathrm{Ra}<0.036 \mathrm{um}$ ) with high material ratios (Abbot-Firestone curves) and convenient tribological properties were found. Ongoing research is focused on studies of milling and belt grinding technology, and fatigue properties in tensile R 0.1 mode of loading. Copyright (C) VBRI Press.
\end{abstract}

Keywords: Titanium, EBM, cutting, surface, mechanical properties.

\section{Introduction}

Metal orthopaedic joint implants (e.g. knee joints) are used worldwide and their total number of surgical applications grows each year [1-9]. The replacements can be either CNC machined from solid blocks of material (with a conversion of $80 \%$ material into chips), or wrought, cast, fabricated by using powder metallurgy and powder injection molding. However, all unified standard products do not meet the criteria for so-called custom designed implant components that can be lighter and even stronger, with a longer life use. From the late 80 's of the last century hundreds of the rapid prototyping emerged and they started a real revolution in the freeform design and fabrication of complex shape products [10]. The new self-assembly technologies with a powerful computer support use sintering or melting powder layers made by a laser or an electron beam. Solid and porous material structures are widely used. Today, the 3D highly porous titanium structures are also used e.g. for maxillofacial and orthopedic surgery because of their excellent mechanical properties similar to those of human bone and their facilitation of bone ingrowth within 60 days [11]. The versatility of the EBM process can be demonstrated by a production of standard implants and the custom implants coupled with porous sections. The well-controlled porous structures, combined with rough surfaces and bone-like apatite layers, produce improved bone ingrowth and apposition [12]. The fully dense pure titanium and weak textured parts with high strength and convenient ductility were fabricated using the same laser energy density but different laser powers in [13].

A few works have dealt with the friction coefficients of the new e-beam titanium specimens, but without machining they were significantly higher compared to the sandblasted specimens and in the same range of the titanium plasma sprayed control [14]. A study of machined surfaces with advanced parameters including e.g. three-steps tumbling was missing.

The cutting forces were studied recently in the work [15] with respect to the dynamic recrystallization in $\beta$-phase when turning, so the evolution of grain size can affect the machining process and tool wear.

The commercial annealed alloy Ti6Al4V ELI (Sandvik Bioline) was used for turning tests and LN2 or $\mathrm{CO} 2$ cooling [16]. The best results in terms of surface defects, surface topography and altered layer were obtained when using $\mathrm{N} 2$ cooled at $-150{ }^{\circ} \mathrm{C}$. 
This paper deals with the electron beam melting technology that uses a vacuum chamber, electron gun and powder material to be melted and sintered into solid structures for high loading of big joints. The main effort is devoted to the quantification of production precision, surface quality after sintering, turning and tumbling, material and technological properties, including tribological characteristics.

\section{Experimental}

To study the whole production technology, the standard metal powder Arcam Ti6Al4V-ELI for implants was used - Fig. 1, Table 1. The Arcam Q10 plus and technological regime Arcam 4325 (vacuum pressure 4.10-3 mbar, voltage 59.6-59.8 kV, current 2.7-2.9 A, thickness of layers $0.5 \mathrm{~mm}$, maximal beam power $3,000 \mathrm{~W}$, beam diameter $100 \mu \mathrm{m}$, maximal translation speed $8000 \mathrm{~m} / \mathrm{s}$, helium consumption 1 liter per hour in building process) were used for production of cylindrical samples of $\phi 14-120 \mathrm{~mm}$ according to the Fig. 1.
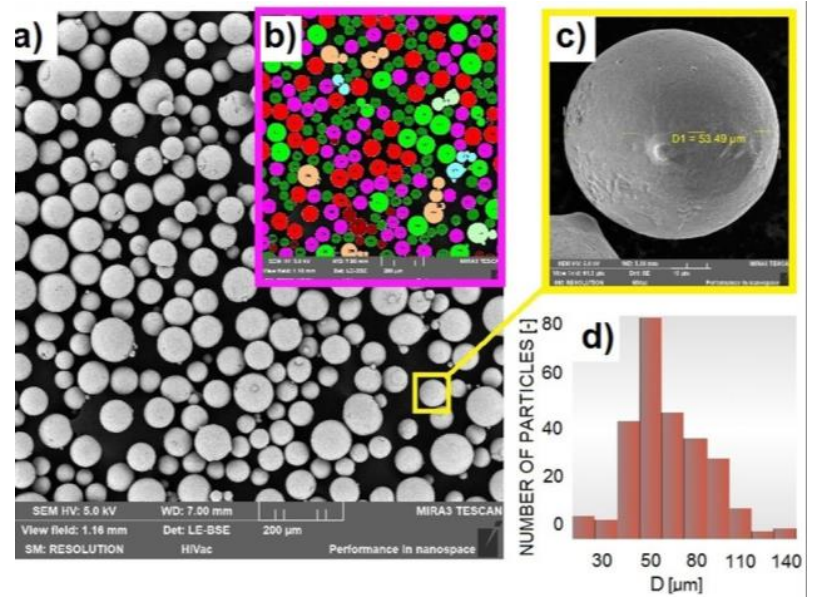

Fig. 1. An analysis of the titanium powder for EBM technology. (a) SEM overview, (b) statistical identification of the particles, (c) a particle, d) distribution histogram.

Table 1. Chemical composition of the Ti- alloy [18].

\begin{tabular}{c|c|c|c|c|c|c|c|c}
\hline & $\mathbf{A l}$ & $\mathbf{V}$ & $\mathbf{C}$ & $\mathbf{F e}$ & $\mathbf{O}$ & $\mathbf{N}$ & $\mathbf{H}$ & $\mathbf{T i}$ \\
\hline$[\mathrm{hm} . \%]$ & 6.0 & 4.0 & 0.03 & 0.1 & 0.1 & 0.01 & 0.003 & rest \\
\hline
\end{tabular}

The Arcam Q10plus and technological regime Arcam 4325 (vacuum pressure 4.10-3 mbar, voltage 59.6-59.8 kV, current 2.7-2.9 A, thickness of layers $0.5 \mathrm{~mm}$, maximal beam power $3,000 \mathrm{~W}$, beam diameter $100 \mu \mathrm{m}$, maximal translation speed $8000 \mathrm{~m} / \mathrm{s}$, helium consumption 1 liter per hour - in building process) were used for production of cylindrical samples of $\phi 14-120$ $\mathrm{mm}$ according to the Fig. 2.

The universal SU50A turning machine was used for machining and tribological experiments. The tool holder PCLNR $2020 \mathrm{~K}$ and the CNMG 120404ER-SI 8030 cutting inserts working at cutting speed $48 \mathrm{~m} / \mathrm{min}$, at the cutting depth $1.0 \mathrm{~mm}$. The feeds per rotation were set in the range $0.05-0.40 \mathrm{~mm}$ and dry machining was used (for a prevention of the surface contamination with cooling fluid).

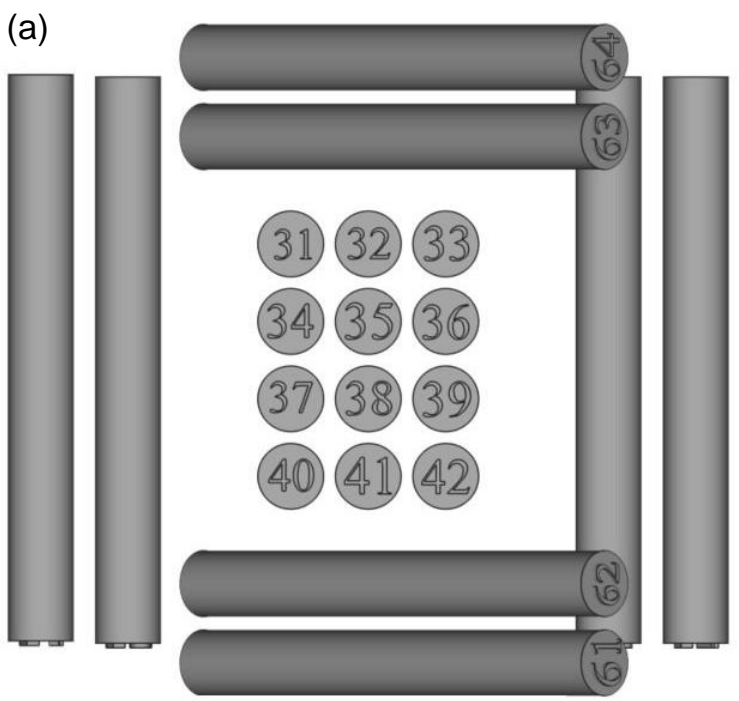

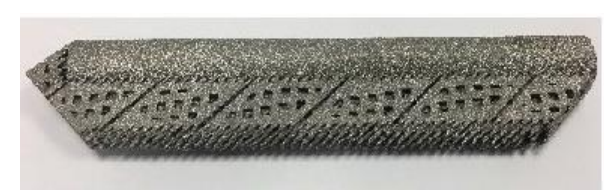

(b)

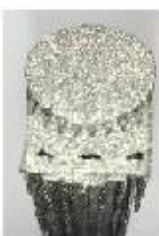

(c)
Fig. 2. Production of the samples: (a) space positions in the chamber, (b-c) metal supports of the samples (preventing deflections of the samples when melting of powder).

At the novel tribological tests, reversible motions at speeds from -5 to $5 \mathrm{~mm} / \mathrm{s}$ were used, repeated 20 times at each surface and MiniTab v.15 was utilised for their statistical assessments. The reason for that testing can be seen in the physically closer kinematics for real joint motion compared to the standard tribological tests (pin on disc, 3-balls tests, etc.).

The hydraulic testing machine ZD40/400kN (HBM /Germany) equipped with SW M-TEST v.1.7 for tensile tests of metal materials complying with the standard EN 10001-2 was used for the tensile tests.

The drag finishing machine DF5 (OTEC, Germany) for final tumbling polishing with abrasives DBS 6/6, KM 12, M5/400 DIA (each working for 20 minutes, at regimes of reverse movements of $+40 /-20 \mathrm{rpm} / \mathrm{min}$ ).

The high-resolution microscope Alicona IF GF-5 was used for evaluations of 2D/3D surface roughness, topography, surface texture (Abbott-Firestone curve with material ratios), wear of cutting tools, including the advanced analyses of surface gradients and volumetric measurements. For measurements of basic geometrical shape parameters and dimensional accuracy the Mahr 420 microscope showed to be effective and precise.

Finally, the analytical electron microscope TESCAN MIRA 3 was used for the material analyses. 


\section{Results and discussion}

A typical outer surface of the produced EBM sample can be seen in Fig. 3. The average roughness for the all as built samples was within the range of $23-31 \mu \mathrm{m}$.
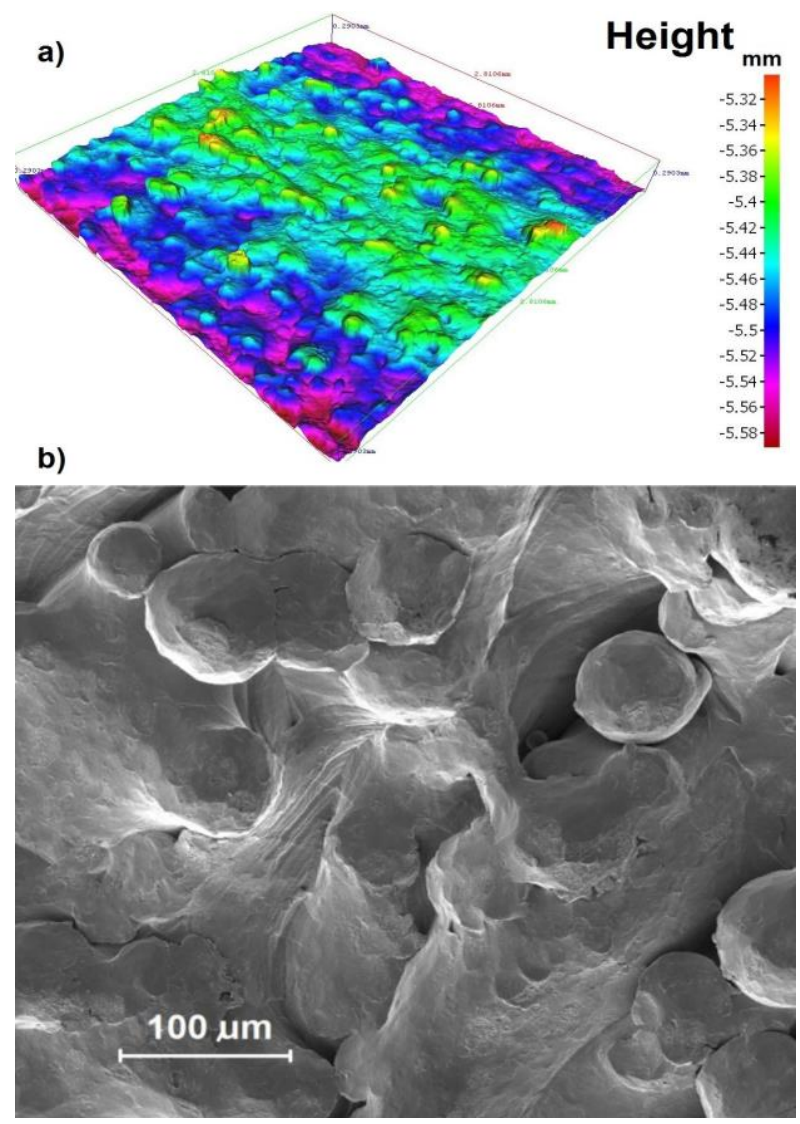

Fig. 3. As built surface of the EBM samples. a) surface topography a) REM of the surface - joined and semi-joined particles, cracks.

The best straightness was reached for the horizontal positions of samples and the best cylindricity was found for the upright position (both corresponding to ISO IT 12). The typical Widmanstätten pattern of $\alpha$-phases and residual $\beta$-phases (about 7\%) was found by the EBDS analyses. The cutting forces showed progressive trends with increasing feed per rotation for all tested samples and the ratios $\mathrm{Fc} / \mathrm{F}$ (F-total force) were in the range from 0.66 up to 0.92 . The specific cutting force $\mathrm{k}_{\mathrm{c}}$ was expressed as a ratio of the cutting force $\mathrm{Fc}$ and the un-deformed chip cross-section $A_{D}$ (depending on depth of cut $\mathrm{a}_{\mathrm{p}}$ and feed $\mathrm{f}$ according to the equation (1):

$$
k_{c}=\frac{F_{c}}{A_{D}}=\frac{F_{c}}{a_{p} \cdot f}=c . f^{a} .
$$

Nevertheless, the calculated values of specific cutting force reached very high values, corresponding to standard hardened materials or superalloys - Fig. 4, what means that the material is difficult to machine and high wear of cutting tools can be expected. More detail can be seen in [19].

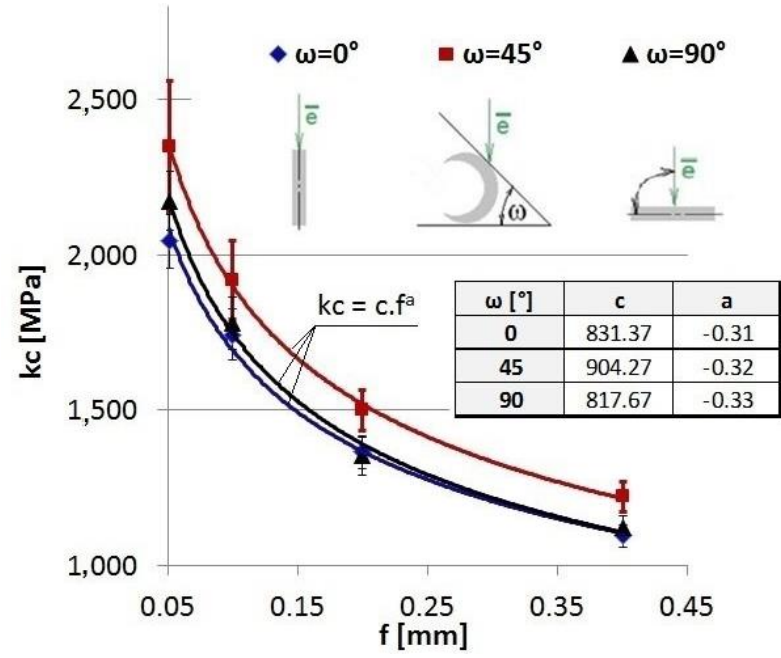

Fig. 4. Specific cutting forces as function of feeds per rotation (equal to chip thickness) and inclination angle between the electron beam and longitudinal axis of the samples.

Table 2. Selected surface roughness parameters after machining and tumbling (results for the inclination angle $0^{\circ}$ ).

\begin{tabular}{|c|c|c|c|c|c|}
\hline Feed & \multicolumn{4}{|c|}{$\mathrm{f}[\mathrm{mm}]$} & after \\
\hline Surface & 0.05 & 0.1 & 0.2 & 0.40 & tumbling \\
\hline $\operatorname{Ra}[\mu \mathrm{m}]$ & 1.46 & 1.06 & 2.79 & 5.78 & 0.03 \\
\hline $\mathrm{Rq}[\mu \mathrm{m}]$ & 2.03 & 1.35 & 3.38 & 6.78 & 0.04 \\
\hline $\mathrm{Rz}[\mu \mathrm{m}]$ & 14.3 & 7.67 & 16.6 & 31.4 & 0.20 \\
\hline $\mathrm{Rk}[\mu \mathrm{m}]$ & 3.87 & 3.34 & 9.21 & 20.7 & 0.09 \\
\hline $\operatorname{Rpk}[\mu \mathrm{m}]$ & 2.96 & 1.54 & 2.71 & 2.27 & 0.04 \\
\hline $\operatorname{Rvk}[\mu \mathrm{m}]$ & 2.94 & 1.31 & 2.37 & 6.34 & 0.03 \\
\hline $\mathrm{Rmr}_{1}[\%]$ & 13.8 & 10.9 & 12.9 & 4.36 & 10.5 \\
\hline $\mathrm{Rmr}_{2}[\%]$ & 88.4 & 91.1 & 94.1 & 94.5 & 90.55 \\
\hline
\end{tabular}
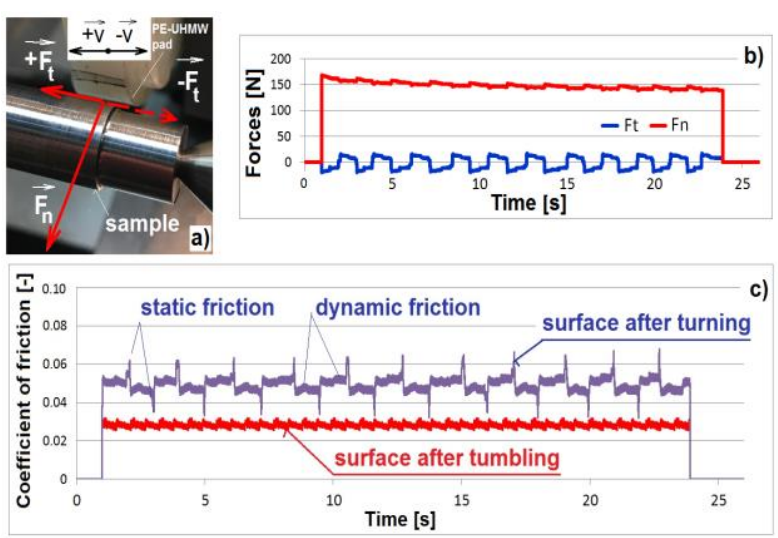

Fig. 5. Tribological tests: a) test arrangement, b) an example of normal and tangential forces, c) description of frictions.

The tribological tests were conducted reversibly with the standard PE-UHMW polyethylene pad, in the direction perpendicularly to the machined surface Fig. 5, because the static friction could be identified in the motion dead ends. However, the machined and tumbled surfaces suppressed those peaks due to its glossy surface and excellent quality - Table 2, Fig. 5. Anyway, the inclination angle when sintering and quality of the surface affects the friction characteristics 
- Fig. 6. The tensile tests showed a very good consistency and low dispersion of data - Fig. 7, Table 3. All the tested samples exhibited a ductile mechanism of plastic deformation when loaded to the limits, without any typical upper or lower yield strength characteristic, but with high tensile strengths - Fig. 7 . The morphology of the fractured surfaces confirmed the crucial role of sintering technology for the crack initiation and propagation - Fig. 7c. The differences in the mechanical properties should be reflected in the custom designed implant dimensions and quality Fig. 8.

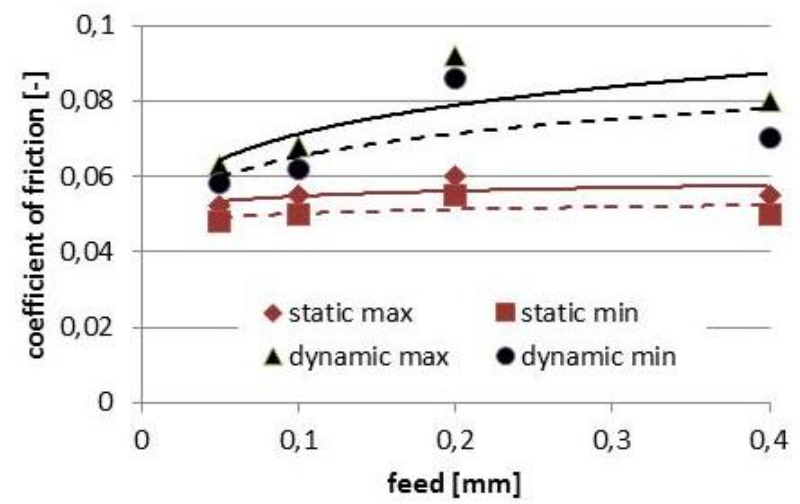

(a)

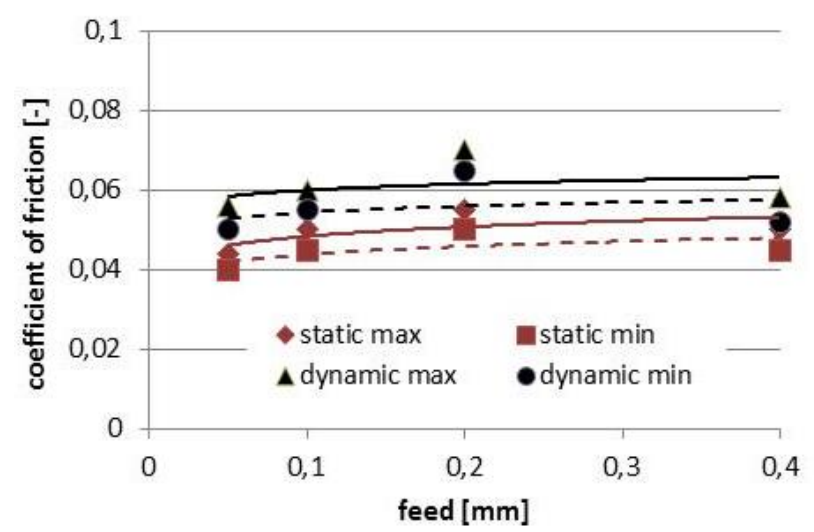

(b)

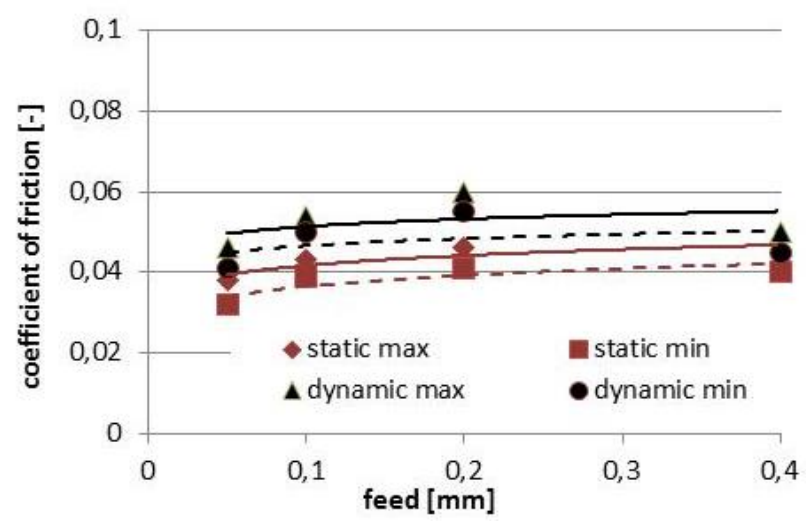

(c)

Fig. 6. The friction as function of feed per rotation and orientation of samples: a) $\omega=0^{\circ}$ b) $\omega=90^{\circ}$ c) $\omega=45^{\circ}$. Traversal speed $v= \pm 5 \mathrm{~mm} / \mathrm{s}$, dry sliding conditions.

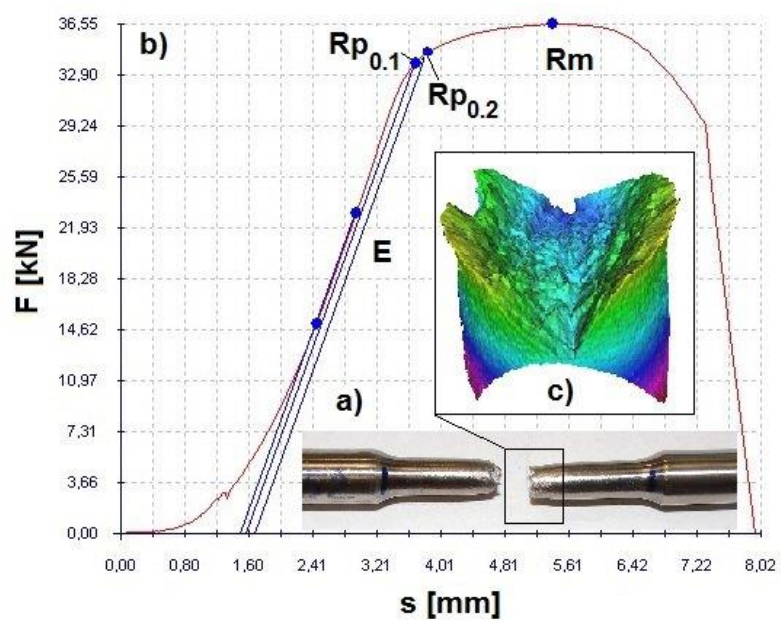

Fig. 7. Example of tensile test: a) ruptured sample b) tensile diagram and position of parameters c) morphology of the fracture.

Table 3. Mechanical properties of the tested samples.

\begin{tabular}{|c|c|c|c|c|}
\hline \multirow{2}{*}{ Ti6AI4V ELI } & \multicolumn{4}{|c|}{ ArcamQ10plus } \\
\hline & Arcam & $\omega=0^{\circ}$ & $\omega=45^{\circ}$ & $\omega=90^{\circ}$ \\
\hline $\begin{array}{l}\text { Yield stress } \\
\text { Rp0,2 [MPa] }\end{array}$ & $\begin{array}{c}950 \\
802^{*} \\
1100-1150^{* *}\end{array}$ & 892-941 & $967-970$ & 849-913 \\
\hline $\begin{array}{l}\text { Ultimate } \\
\text { Tensile strength } \\
\text { Rm [MPa] }\end{array}$ & $\begin{array}{c}970 \\
904 * \\
1150-1200^{* *}\end{array}$ & 985-986 & $1,006-1,012$ & 950-962 \\
\hline Elongation [\%] & $\begin{array}{c}16 \\
14^{*} \\
16-25^{* *}\end{array}$ & $10.00-11.43$ & $11.43-12.86$ & $11.42-11.43$ \\
\hline $\begin{array}{l}\text { Rockwell } \\
\text { hardness [HRC] }\end{array}$ & $\begin{array}{c}32 \\
37-40 * *\end{array}$ & $45-48$ & $47-49$ & $36-42$ \\
\hline $\begin{array}{l}\text { Fatigue strength } \\
\text { at } 600 \mathrm{MPa} \\
{[-]}\end{array}$ & $>10$ mil. & - & - & - \\
\hline $\begin{array}{l}\text { Modulus of } \\
\text { elasticity [GPa] }\end{array}$ & 120 & $118-120$ & $118-122$ & $116-118$ \\
\hline
\end{tabular}

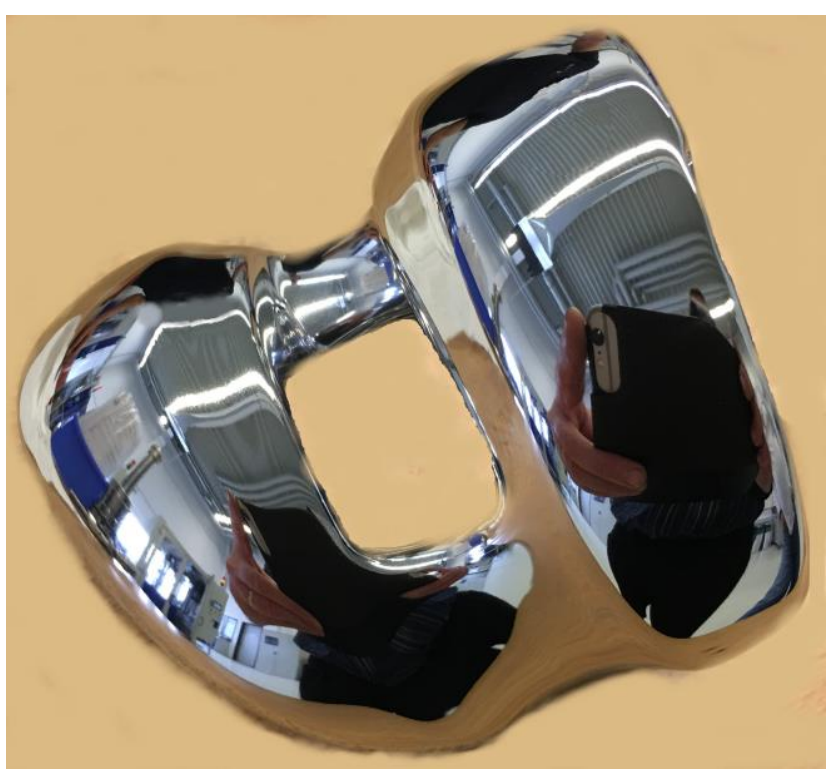

Fig. 8. Example of the knee implant and its final surface quality. 


\section{Discussion and conclusions}

This work confirmed an important role of the technologies on the quality of the EBM material and its mechanical properties. The material structures reflected their sintering technologies, mechanical and tribological behaviour what can affect the real applications. The following conclusions can be made:

- the inclination angle in the build chamber affected the all studied parameters;

- the material consists of very homogenous acicular $\alpha$-phase and residual $\beta$-phase (7\%), but some pores and cracks can also be found,

- static and dynamic friction depend on the surface roughness, the tumbling technology gave minimal friction (coefficient of friction 0.023-0.032),

- the tensile strengths were high (up to1,012 $\mathrm{MPa}$ ) and statistically consistent,

- the material is very abrasive, difficult to machine, accompanied with high specific forces and intensive wear,

- $\quad$ excellent surfaces $(\operatorname{Ra}<0.036 \mu \mathrm{m})$ can be reached with the technology of machining and tumbling, but the machining can't be omitted (due to prevention of shape precision - roundness, cylindricity).

\section{Future perspectives}

The following research is focused on studies of milling and belt grinding technology, and fatigue properties in tensile R 0.1 mode of loading. The fatigue tests can more specify the effect of sample inclinations on material properties, crack nucleation and expected reliability of the technology and material.

\section{Acknowledgements}

This research work was supported by the Brno University of Technology, FME, Specific research 2016, with the grant "Research of modern production technologies for specific applications", FSI-S16-3717.

\section{References}

1. ICOR - International Consortium of Orthopaedics Registers. (http://www.icor-initiative.org/about.aspx)

2. American Joint Replacement Registry's (AJRR) 2013 Annual Report on Hip and Knee Arthroplasty Data. http://icjr.net/report_209_ajrr_report.htm\#.VzWmE-SLjh5)

3. Steven, K.; Kevin, O.; Edmund, L.; Fionna, M.; Michael, H.; Projections of Primary and Revision Hip and Knee Arthroplasty in the United States from 2005 to 2030. J Bone Joint Surg Am, 2007, 89, 780 .

4. National Joint Registry for England, Wales, Northern Ireland and the Isle of Man. 12th Annual Report 2015.

(http://www.njrcentre.org.uk/njrcentre/Portals/0/Documents/En gland/Reports/12th\%20annual\%20report/NJR\%20Online\%20A nnual\%20Report\%202015.pdf)

5. National Joint Registry for England, Wales, Northern Ireland and the Isle of Man. NJR StatsOnline 2015. (http://www.njrcentre.org.uk/njrcentre/Healthcareproviders/Acc essingthedata/StatsOnline/NJRStatsOnline/tabid/179/Default.as $\mathrm{px})$

6. Bourne, R. B.; Chesworth, B. M.; Davis, A.M.; Mahomed, N. N.; Charron K. D.,Clin Orthop Relat Res., 2010, 468, 57.
7. Mahoney, O. M.; Kinsey, T., Bone Joint Surg Am., 2010, 92, 1115.

8. Swedish Knee Arthoplasty Register. Annual Report. Lund University. Department of Clinical Sciences, Orthopedics. Skånes University Hospital, Lund. Sweden 40 years: 19752015. ISBN 978-91-88017-04-81.

9. Etkin, C. D.; Springer, B., Arthroplasty Today, 2017, 3, 67.

10. Murr L. E.; Quinones, S. A.; Gaytan, S. M.; Lopez, M. I.; Rodela, A.; Martinez, E. Y.; Hernandez, D. H.; Martinez, E.; Medina, F.; Wicker, R. B., J. Mech. Behav. Biomed. Mater. 2009, 2, 20

11. Ponader, S.; Von Wilmowsky, C.; Widenmayer, M.; Lutz, R.; Heinl, P.; Körner, C.; Singer, R. F.; Nkenke, E.; Neukam, F. W.; Schlegel, K. A., J. Biomed. Mater. Res., Part A, 2010, 92, 56.

12. Li, X.; Luo, Y.; Wang, C.; Zhang, W.; Li, Y., Frontiers of Mechanical Engineering, 2012, 7, 66.

13. Li, X. Van Humbeeck J.; Kruth J., Materials \& Design, 2017 , $116,352$.

14. Biemond, J. E.; Aquarius, R.; Verdonschot, N.; Buma, P., Arch Orthop Trauma Surg., 2011, 131, 711.

15. Arcam Q10 Technical Data [online]. [cit. 2018-07-15]. http://www.arcam.com/wp-content/uploads/Arcam-Q10.pdf

16. Pan, Z.; Shih, D. S.; Tabei, A.; Garmestani, H.; Liang. S. Y., Int. J. Adv. Manuf Technol., 2017, 91, 2673.

17. Sartori, S.; Pezzato, L.; Dabalà, M.; Maurizi Enrici, T.; Mertens, A.; Ghiotti, A.; Bruschi, S., J. Mater. Eng. Perform., 2018, 27, 4810.

18. Buckova, K.; Study of Ti-6Al-4V Alloy Sintering Technology for Implants. Brno 2018. Bachelor work. Brno University of Technology, Faculty of Mechanical Engineering. 101 Supervisor: Prof. Ing. Miroslav Píška, CSc.

19. Svensson, M.; Ackelid, U.; Medical Device Materials V. In: Titanium Alloys Manufactured with Electron Beam Melting Mechanical and Chemical Properties Proceedings from the Materials \& Processes for Medical Devices Conference 2009. Minneapolis, Minnesota, USA, J. Gilbert, (Ed.), 189 